\title{
Spicular arrangement of amyloid in renal biopsy
}

\author{
I. D. ANSELL' AND A. M. JOEKES
}

From the Departments of Pathology and Medicine, Institute of Urology and St Peter's Hospitals, London

SYNOPSIS A spicular arrangement of amyloid on the epithelial aspect of the glomerular basement membrane has been seen to a variable degree in silver-stained sections of renal biopsies in eight of $\bar{\omega}$ 38 patients with amyloidosis. Electron microscopical examination revealed a spectrum of appearances of the amyloid fibrils which would account for this finding. Only two of these eight patients had amyloidosis secondary to chronic infection, a much lower proportion than in the group as a whole. N The possibility of confusion with membranous nephropathy is discussed with relevance to possible $\vec{N}$ modes of treatment.

Spikes on the epithelial aspect of the glomerular basement membrane stained by hexamine-silver are considered pathognomic of membranous nephropathy (Ehrenreich and Churg, 1968). Two cases of renal amyloid in which such spikes were seen, and a diagnosis of membranous nephropathy initially entertained, prompted a review of our renal biopsy material from patients with amyloidosis.

\section{Methods}

Renal biopsy material from 38 patients with renal amyloidosis was examined. ${ }^{2}$

The presence of amyloid in paraffin-embedded sections was confirmed by the demonstration of specific yellow fluorescence following staining with thioflavine $T$ (Vassar and Culling, 1959) and of yellow-green dichroism after staining with Sirius red (Llewellyn, 1970) and examination between crossed polars. Two-micron sections were stained by the hexamine-silver technique and examined carefully for the presence of spikes on the epithelial aspect of the basement membrane. Glomeruli were present in araldite-embedded material from eight of these cases. Ultrathin sections were cut on an LKB ultramicrotome, stained with uranyl acetate and lead citrate, and examined with an EM6M electron microscope.

\section{Results}

A spicular arrangement of silver-positive material ${ }^{1}$ Present address: Department of Histopathology, Royal Postgraduate Medical School, Hammersmith Hospital Medical School, London W12.

'The majority of these patients are included in a clinical study of renal amyloid (Triger and Joekes, 1973).

Received for publication 10 October 1972. on the epithelial aspect of the basement membrane $\stackrel{\circ}{工}$ was seen in eight of the biopsies (see Table). The number of glomeruli affected varied considerably as did the morphology of the spikes. In the one case (case 44) in which all glomeruli were affected the histological appearance was indistinguishable from that seen in membranous nephropathy (Fig. 1). Ig $\overrightarrow{0}$ the others the spikes were fewer and/or coarse N (Figs. 2 and 3). In one case (case 38) in addition t8 the foci of spikes there were other areas which appeared to be formed from fusion of a pallisaded array of parallel spikes (Fig. 4). In those cases in which serial sections were available the spikes were shown to occur where amyloid was present.

In all nine specimens examined with the electron microscope the fibrillary nature of the amyloid (Cohen and Calkins, 1959) was confirmed. Three of these cases (cases 38,44 , and 45) were from patients in whom spikes had been seen with light microscopy (see Table) and in two cases (cases 38 and 44) a distinctive distribution of amyloid fibrils in parallel arrays arranged at right angles to the basement membrane could be seen (Figs. 5, 6, 7, and 8). The lamina densa remained discrete in the region of amyloid deposition and there was no spicular extension of basement membrane material to account for the appearance in silver stains. Overlying epithelial cells showed extensive foot process fusion $\mathcal{N}$ and prominence both of the Golgi apparatus and $N$ granular endoplasmic reticulum (Fig. 7). In many N areas the cell membrane of the epithelial cells appeared to be deficient in the region of the closely aggregated amyloid fibrils (Fig. 6). In the third case (case 45) glomeruli were extensively damaged and spikes had been very infrequent in the light microscope preparations. In the remaining five cases in which glomeruli were available for examination by 


\begin{tabular}{|c|c|c|c|c|c|}
\hline \multirow[t]{2}{*}{ Case No. ${ }^{1}$} & \multicolumn{2}{|c|}{ Hexamine-silver-stained Section } & \multicolumn{2}{|c|}{ Electron Microscopy } & \multirow[t]{2}{*}{ Clinical Variety of Amyloid } \\
\hline & $\begin{array}{l}\text { Number of } \\
\text { Glomeruli Present }\end{array}$ & $\begin{array}{l}\text { Number of } \\
\text { Glomeruli with Spikes }\end{array}$ & $\begin{array}{l}\text { Number of } \\
\text { Glomeruli }\end{array}$ & $\begin{array}{l}\text { Number and } \\
\text { Type of Spike }\end{array}$ & \\
\hline $\begin{array}{l}8 \\
20 \\
23 \\
33 \\
32 \\
38 \\
44 \\
45 \\
41 \\
42 \\
43 \\
\text { Not included } \\
\text { Not included }\end{array}$ & $\begin{array}{r}60 \\
9 \\
21 \\
37 \\
52 \\
22 \\
31 \\
14 \\
42 \\
8 \\
12 \\
24 \\
18\end{array}$ & $\begin{array}{r}2 \\
3 \\
14 \\
7 \\
6 \\
18 \\
31 \\
1 \\
0 \\
0 \\
0 \\
0 \\
0\end{array}$ & $\begin{array}{r}\overline{-} \\
\overline{-} \\
\overline{0} \\
6 \\
8 \\
8 \\
9 \\
12 \\
4 \\
3 \\
1\end{array}$ & $\begin{array}{l}\overline{-} \\
\overline{-} \\
\overline{0} \\
3 \\
8 \\
0^{2} \\
2 \text { blunt } \\
1 \text { blunt } \\
2 \text { blunt } \\
1 \text { blunt } \\
1 \text { blunt }\end{array}$ & $\begin{array}{l}\text { Secondary to tuberculosis } \\
\text { Secondary to tuberculosis } \\
\text { Primary } \\
\text { Familial mediterranean fever } \\
\text { Primary } \\
\text { Primary } \\
\text { Primary } \\
\text { Secondary to rheumatoid arthritis } \\
\text { Primary } \\
\text { Secondary to bronchiectasis } \\
\text { Familial mediterranean fever } \\
\text { Secondary to tuberculosis } \\
\text { Secondary to chronic pyelonephritis of other } \\
\text { kidney }\end{array}$ \\
\hline
\end{tabular}

Table Cases with spikes and/or tissue examined by electron microscopy

${ }^{2}$ From Triger and Joekes (in press)

2Glomeruli very sclerosed

electron microscopy occasional parallel arrays of amyloid fibrils were seen but these were more infrequent and blunter than those present in the cases in which silver-positive spikes were also seen by light microscopy (Fig. 9).

\section{Discussion}

The name membranous glomerulonephritis was introduced by Bell in 1946 to indicate the histological feature of glomerular capillary wall thickening seen in some patients with the nephrotic syndrome. As such the term is not a distinct entity since capillary wall thickening may be seen in diffuse diabetic glomerulosclerosis, amyloidosis, and systemic lupus erythematosus as well as in some varieties of glomerulonephritis. In 1957 Jones used the same term for a group of patients with the nephrotic syndrome in whom renal biopsy showed thickened capillary walls with conventional staining and silverpositive spikes on the epithelial aspect of the basement membrane in hexamine-silver-stained sections. Subsequently Movat and McGregor (1959) using electron microscopy demonstrated processes of basement membrane material extending outwards between electron-dense deposits. Immunofluorescent studies demonstrated that these deposits contained immunoglobulins and complement (Mellors and Ortega, 1956; Lachmann, Muller-Eberhard, Kunkel, and Paronetto, 1962). In its early stages this condition is focal and local in nature, and Ehrenreich and Churg (1968) have recommended that sections from all renal biopsies should be stained with hexamine-silver and routinely scrutinized carefully for the presence of spikes in order to detect early involvement. They also suggested substitution of the term 'nephropathy' for glomerulonephritis as inflammatory changes are not a significant histological feature. Even more recently yet another term, 'epimembranous' or 'extramembranous' nephropathy, has been proposed (Churg, Habib, and White, 1970) in which the subepithelial nature of the thickening is stressed.

The cases reported here demonstrate that the appearance of spikes is not, as hitherto thought, diagnostic of membranous nephropathy and emphasizes the importance of staining all renal biopsies for amyloid. The specific demonstration of amyloid remains a matter of debate since many techniques stain substances other than amyloid and the staining properties of amyloid itself change with increasing age (Lendrum, Slidders, and Fraser, 1972). Many writers consider that yellow-green dichroism of Sirius- or Congo-red-stained sections viewed between cross polars is specific for amyloid (Cooper, 1969; Cohen, Calkins, and Levene, 1959) although Klatskin (1969) found similar fluorescence in many normal tissues. This non-specific green fluorescence was present in material which had been fixed in solutions other than neutral formalin (the fixative used in our laboratory) and was rarely seen when formalin fixation was used.

The uptake of stains often regarded as specific amyloid by postmature and pseudo-collagen (Lendrum, 1969; Lendrum, et al, 1972) is not frequently a problem in renal biopsy work as material is usually obtained early in the natural history of the disease before significant sclerosis of glomeruli would be expected to have occurred. Staining of adjacent sections with thioflavine $T$ will give further help in the identification of amyloid (Klatskin, 1969).

Although there have been no specific descriptions of spikes in renal amyloid, Movat in 1960 described 


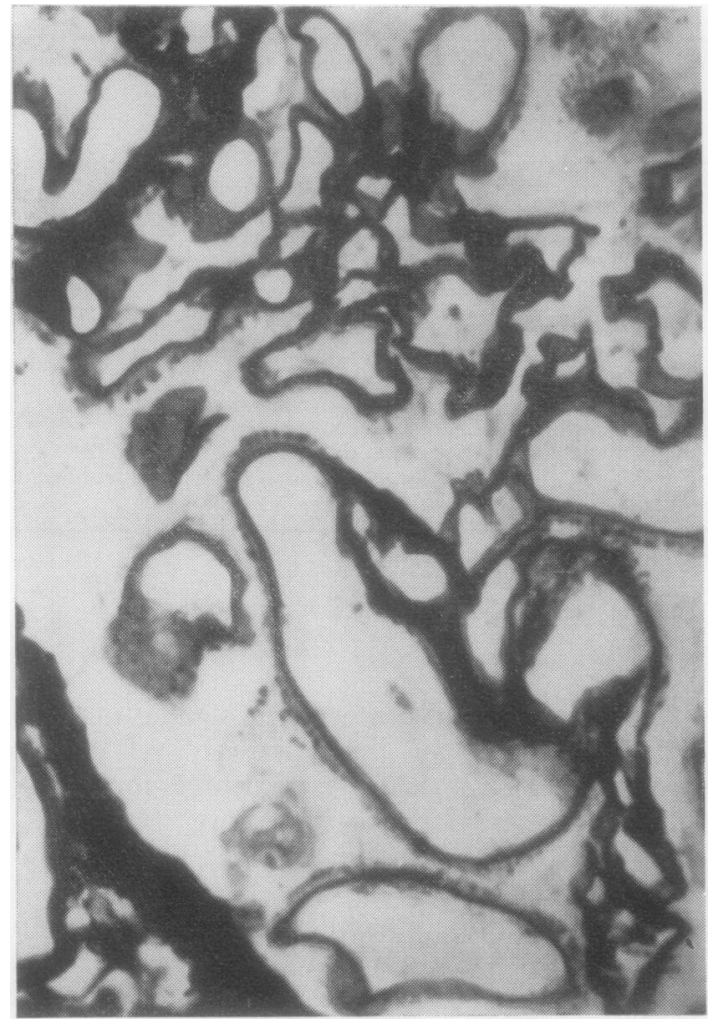

Fig. 1 Case 44: numerous spikes on epithelial aspect of basement membrane mimicking membranous nephropathy (hexamine silver $\times 560$ ).

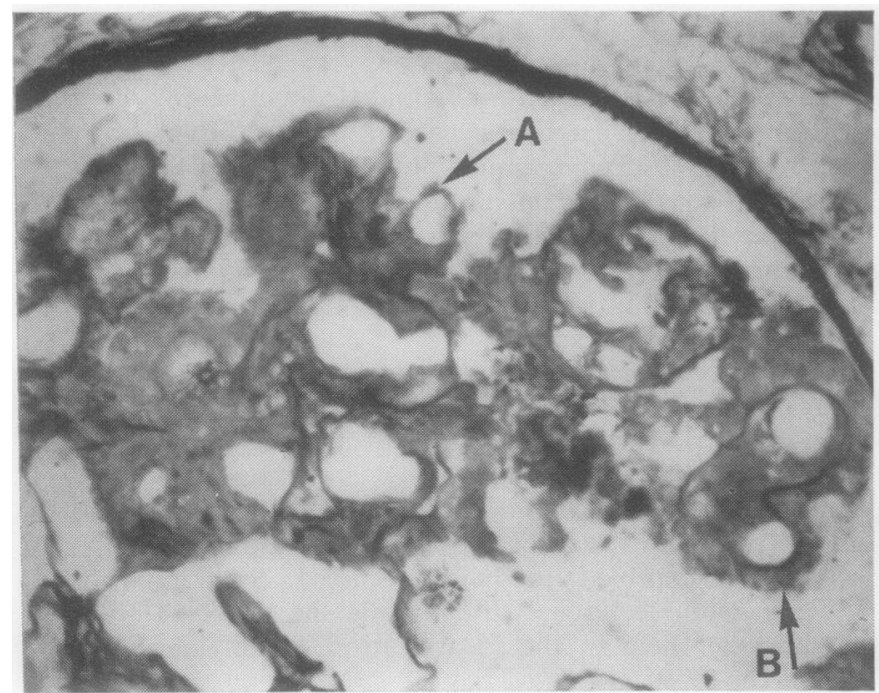

Fig. 4 Case 38: indistinct spikes (A) and areas of apparent fusion of spikes $(\mathrm{B})$ (hexamine silver $\times 472$ ).

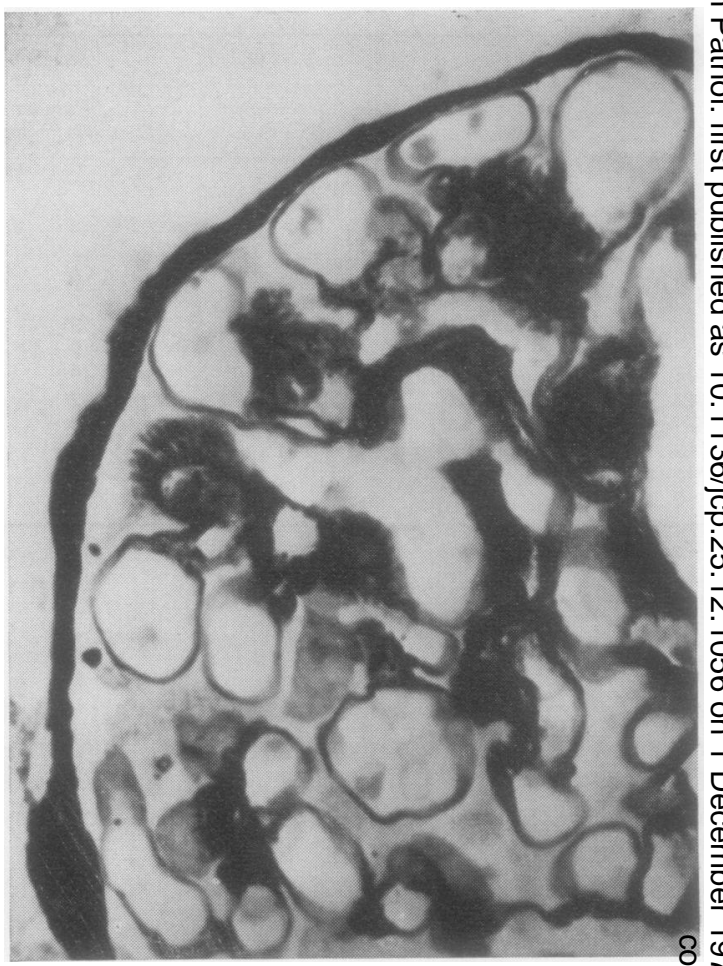

Fig. 2 Case 33: scanty more filamentous epithelial spikes (hexamine silver $\times 375$ ).

은

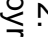

흘이잉

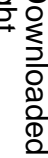

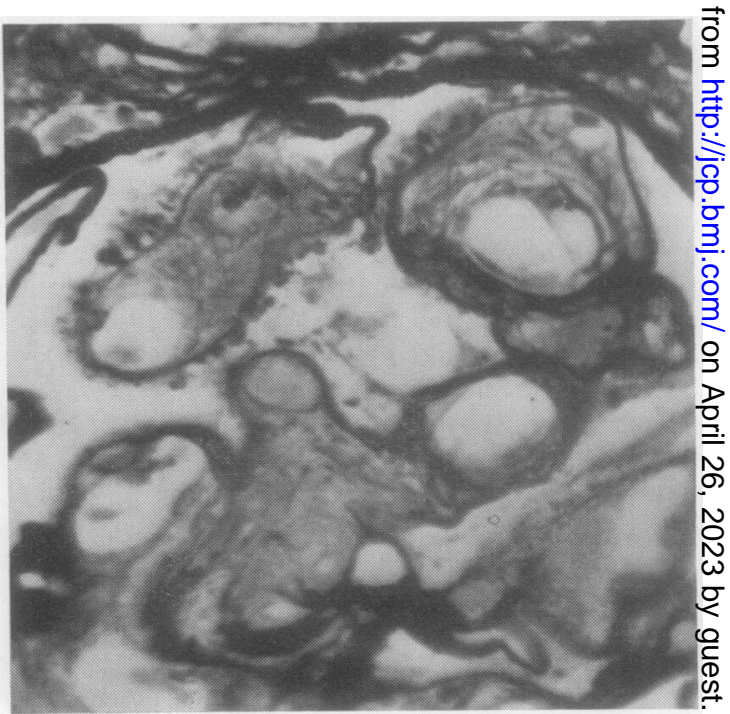

Fig. 3 Case 32: scanty coarse epithelial spikes (hexamine silver $\times 566$ ). 

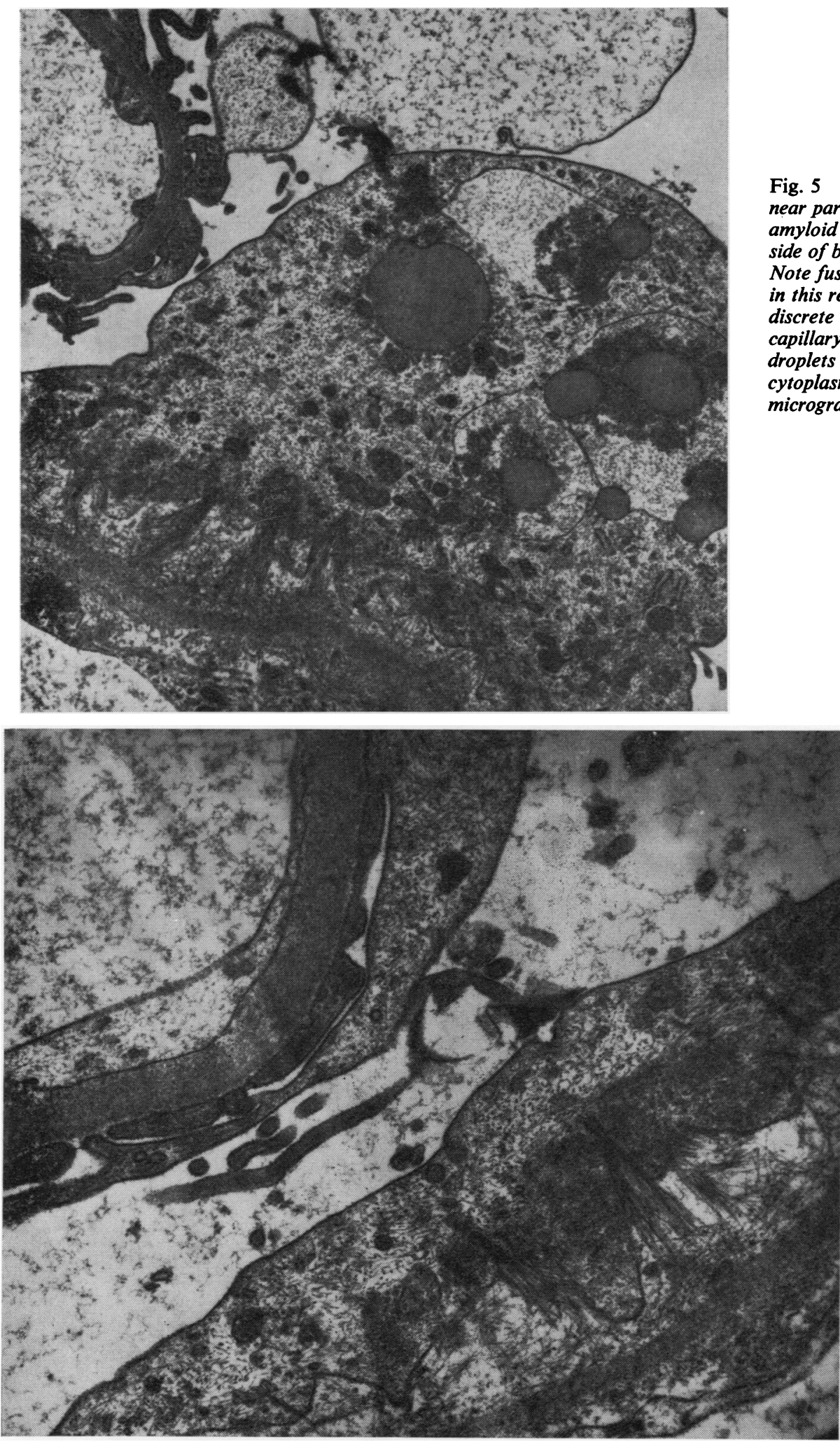

Fig. 5 Case 44: focus of near parallel aggregates of amyloid fibrils on epithelial side of basement membrane. Note fusion of foot processes in this region (they are discrete in the adjacent normal capillary loop) and lipid droplets within epithelial cell cytoplasm (electron micrograph $\times 12000$ ).
Fig. 6 Case 44: higher power view of similar area seen in Figure 5. Near parallel arrays of amyloid fibrils on epithelial aspect of discrete lamina densa. Note apparent deficiency of epithelial cell membrane in region of amyloid (electron micrograph $\times 22000)$. 


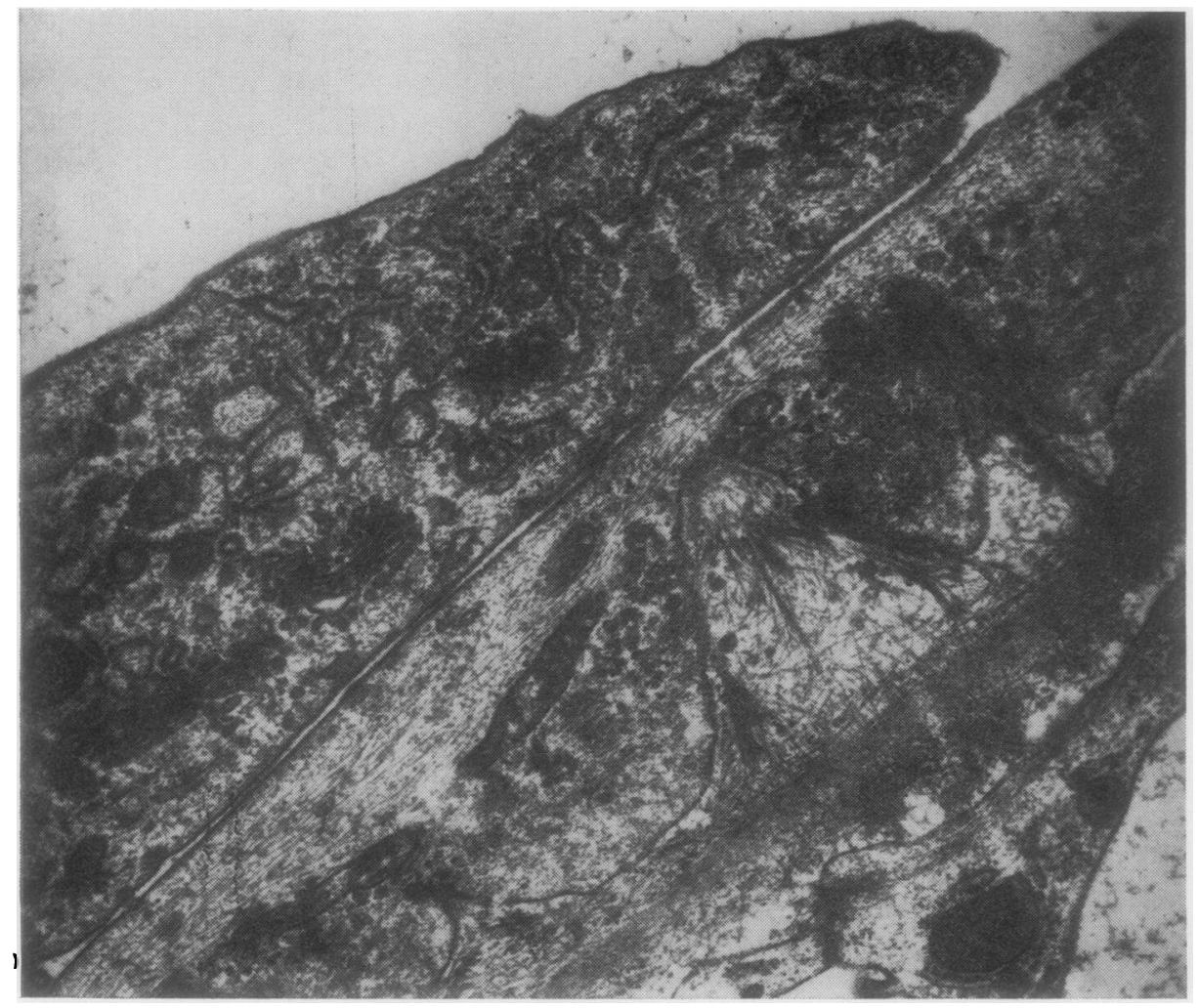

Fig. 7 Case 44: fused 흠 foot processes and prominent Golgi and granular endoplasmic reticulum of epithelial cही। (electron micrograph $\times 26000)$.

Fig. 8 Case 38

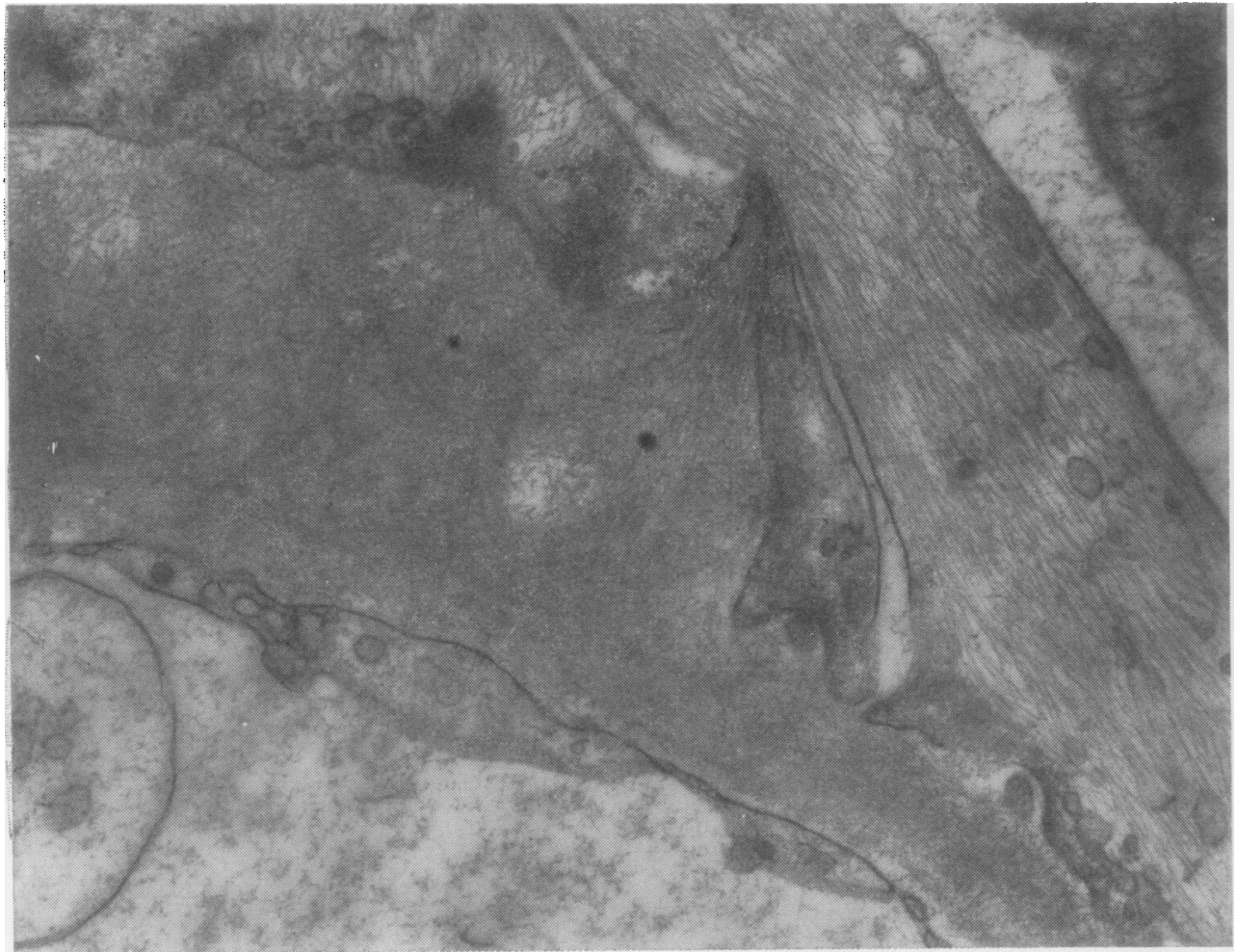

less frequent and hless aggregated collection of amyloid fibrils 융 (electron microgkeph $\times 33000$ ). 


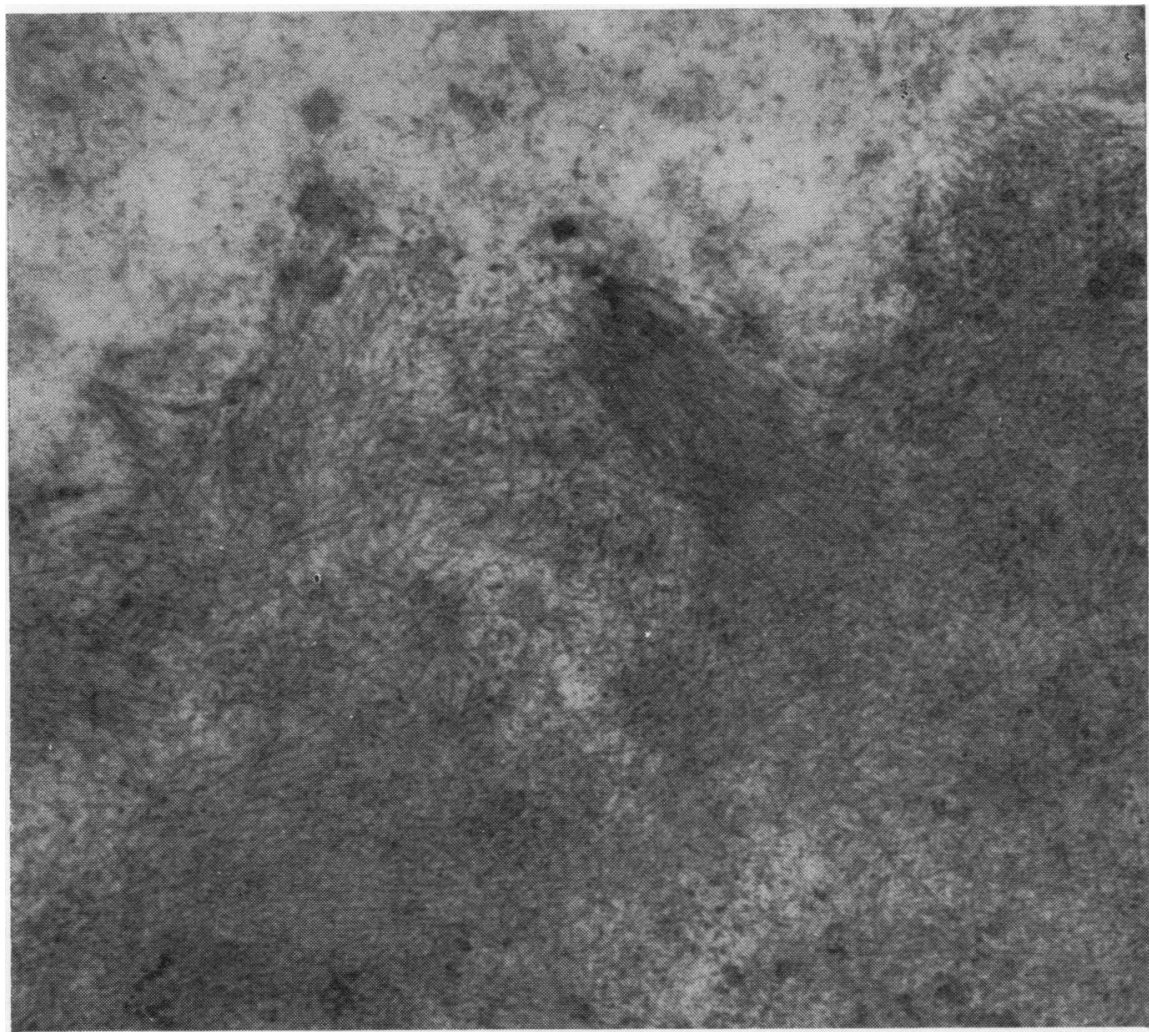

Fig. 9 Case 43: rare occurrence of near parallel amyloid fibrils in case in which no spikes are seen with light microscopy (electron micrograph $\times$ 34000).

silver stains and electron microscopical examination of three cases of renal amyloid secondary to chronic suppuration. One of the cases illustrated had the appearance in silver stains seen in case 38 (Fig. 4) and the electron micrographs were also very similar to those in our case. However, no mention of possible confusion with membranous nephropathy was made. Similar blunt spikes are pictured by Shirahama and Cohen (1967) who also drew attention to the apparent loss of epithelial cell membranes in this area (Fig. 6). They postulated that this loss of membrane might represent sites of extrusion of amyloid manufactured within epithelial cells and ultrastructurally these cells certainly appear to be actively synthetic with prominent granular endoplasmic reticulum and Golgi apparatus (Fig. 7). Amyloid is not usually stained by silver impregnation techniques but in most situations amyloid fibrils are arranged in a very haphazard manner and it is possible that the parallel arrangement of the amyloid fibrils in these cases has in some manner increased their affinity for silver.

The distinction between membranous nephropathy and renal amyloid is of more than academic importance on two accounts. Firstly proteinuria has been reported to disappear on treating the cause of the amyloid (Lowenstein and Gallo, 1970) and the rate of renal damage will certainly be decreased. Secondly, although some series have shown no response of membranous nephropathy to steroids either alone (Black, Rose, and Brewer, 1970) or in combination with azathioprine (Rose and Black, 1971), small series in which there has been response to steroid therapy have been reported (Rastogi, Hart-Mercer, and Kerr, 1969; Bariéty, Samarcq, Lagrue, Fritel, and Milliez, 1968). The use of these drugs with their potentially dangerous side effects should be avoided whenever possible, and some workers even consider that steroids may actually accelerate the progress of renal amyloid deposition (Cohen, 1967), although Maxwell, Adams, and Goldman (1964) found no evidence of either improvement or deterioration with this treatment.

The discovery of the spicular deposits in eight patients in a series of 38 with proven renal amyloid involvement is of considerable interest from the point of view of the possible aetiology in the patients with this finding. From the electron microscopic 
evidence it is clear that the spicular deposits seen with silver staining represent amyloid deposition and not basement membrane-like material situated in relation to antibody-antigen complexes as is classically seen in membranous nephropathy. In renal amyloid the fibrils are usually arranged in a rather haphazard manner within the mesangium and on both aspects of the lamina densa of the basement membrane (Shirahama and Cohen, 1967), and, although blunt spikes of somewhat parallel amyloid fibres have been illustrated in earlier papers (Movat, 1960; Shirahama and Cohen, 1967), this particular arrangement has not been commented on.

Although no morphological or histochemical characters of amyloid have hitherto satisfactorily permitted separation of the various clinicopathological syndromes, recent work has shown that the fibres of amyloid may be derived from different serum protein constituents. In amyloid secondary to either prolonged antigenic stimulation or plasma cell dyscrasia the fibrils are derived from the variable part of light chains (Glenner, 1972). In the various primary amyloid syndromes the protein from which the amyloid fibrils are derived is unknown. It is thus of considerable interest to note that in four of the patients with spikes the presumptive diagnosis is primary amyloid, in one familial Mediterranean fever, in one amyloid associated with rheumatoid arthritis, and in two secondary amyloid presumed to be due to underlying infection (pulmonary tuberculosis). It is striking that only two out of the eight patients in whom the spicular amyloid deposition has been found were patients with secondary amyloid, for in the series of 38 patients, 25 were secondary amyloid, eight were diagnosed as primary amyloidosis, and five had familial Mediterranean fever. It could thus be that the spicular arrangement of amyloid fibril is a feature of fibrils not derived from light chains.

We are grateful for the technical assistance of Miss Sue Harvey and the generous financial support of the Medical Research Council and St Peter's Trust.

\section{References}

Bariéty, J., Samarcq, P., Lagrue, G., Fritel, D., and Milliez, P. (1968). Evolution ultrastructurale 'favorable de deux cas de glomérulopathies primitives a depots extra-membraneux diffus. Presse méd., 76, 2179-2182.
Bell, E. T. (1946). Renal Diseases, 1st ed. Lea and Febiger, Phila delphia; Kimpton, London.

Black, D. A. K., Rose, G., and Brewer, D. B. (1970). Controlled tri of prednisone in adult patients with the nephrotic syndrome. Brit. med. J., 3, 421-426.

Churg, J., Habib, R., and White, R. H. R. (1970). Pathology of the nephrotic syndrome in children. Lancet, 1, 1299-1302.

Cohen, A. S. (1967). Amyloidosis. New Engl. J. Med., 277, 522-53此 574-583, 628-638.

Cohen, A. S., Calkins, E., and Levene, C. I. (1959). Studies omp experimental amyloidosis. I. Analysis of histology an staining reactions of casein-induced amyloidosis in the rabbin Amer. J. Path., 35, 971-989.

Cooper, J. H. (1969). An evaluation of current methods for the diagnostic histo-chemistry of amyloid. J. clin. Path., 22410-413.

Ehrenreich, T., and Churg, J. (1968). Pathology of membranous nephropathy. Path. Ann., 3, 145-186.

Glenner, G. C. (1972). The pathogenic and therapeutic implications of the discovery on the immunoglobulin origin of amylois fibrils. Hum. Path., 3, 157-162. Jones, D. B. (1957). Nephrotic glomerulonephritis. Amer J. Path., 33

Klatskin, G. (1969). Nonspecific green birefringence in Congo rec stained tissues. Amer. J. Path., 56, l-13.

Lachmann, P. J., Müller-Eberhard, H. J., Kunkel, H. G., an $\vec{\Phi}$ Paronetto, F. (1962). The localization of in vivo bound com plement in tissue sections. J. exp. Med., 115, 63-82.

Lendrum, A. C. (1969). The validation of fibrin, and its significance iof the story of hyalin. In Trends in Clinical Pathology, Essays in Honour of Gordon Signy, edited by J. L. Stafford, pp. 159-187 British Medical Association, London.

Lendrum, A. C., Slidders, W., and Fraser, D. S. (1972). Renad hyalin: a study of amyloidosis and diabetic fibrinous vasculosi with new staining methods. J. clin. Path., 25, 373-396.

Llewellyn, B. D. (1970). An improved Sirius Red method for amyloid J. med. Lab. Technol., 27, 308-309.

Lowenstein, J., and Gallo, G. (1970). Remission of the nephretic syndrome in renal amyloidosis. New Engl. J. Med., gs 128-132.

Maxwell, M. H., Adams, D. A., and Goldman, R. (1964). Cormo steroid therapy for amyloid nephrotic syndrome. Ann. in Med., 60, 539-555.

Mellors, R. C., and Ortega, L. G. (1956). Analytical pathology. III New observations on the pathogenesis of glomerulonephritis lipid nephrosis, periarteritis nodosa and secondary amyloidosif in man. Amer. J. Path., 32, 455-499.

Movat, H. Z. (1960). The fine structure of the glomerulus in amyळ loidosis. Arch. Path., 69, 323-332.

Movat, H. Z., and McGregor, D. D. (1959). The fine structure of the glomerulus in membranous glomerulonephritis (lipoid neph rosis) in adults. Amer. J. clin. Path., 32, 109-127.

Rastogi, S. P., Hart-Mercer, J., and Kerr, D. N. S. (1969). Idiopathi membranous glomerulonephritis, in adults remission: follow:ing steroid therapy. Quart.J. Med., 38, 335-350.

Rose, G. A., and Black, D. A. K. (1971). Controlled trial of azathioø prine and prednisone in chronic renal disease. Report byo Medical Research Council Working Party. Brit. med. J., 23 239-241.

Shirahama, T., and Cohen, A. S. (1967). Fine structure of the glomero ulus in human and experimental renal amyloidosis. Amer. $J$ F Path., 51, 869-911.

Triger, D. R., and Joekes, A. M. (1973). Renal amyloidosis: ? fourteen-year follow-up. Ouart.J. Med., 42, in press.

Vassar, P. S., and Culling, C. F. A. (1959). Fluorescent stains, with special reference to amyloid and connective tissues. Arch. Path. $68,487-498$. 